\title{
Study on Nutrient Loss Characteristics of Bamboo Forest in Different Configuration Mode
}

\author{
Zhao-Wei Shen ${ }^{1}$,Wen-Shuang Wang ${ }^{1}$,Wang Ran' ${ }^{2}$,Li Gang ${ }^{2}$ \\ ${ }^{1}$ Zhejiang Key Laboratory of Water Conservancy Disaster Prevention and Reduction, Zhejiang \\ Institute of Hydraulics \& Estuary ,Hangzhou ,310020,China
}

2Zhejiang Guang Chuan Engineering Consulting Co., Ltd. ,Hangzhou ,310020,China

\begin{abstract}
Keywords: rainfall; runoff coefficient; nutrient loss;
Abstract: bamboo is an important forest resources in South china. This paper selects the pure bamboo forest, bamboo forest, bamboo Tong Yang Yang Tong - Hemerocallis mixed forest model, the surface of three kinds of configuration modes under the condition of rainfall runoff and nutrient loss (nitrogen and phosphorus), results showed that: (1) 3 configuration modes in pure bamboo forest the maximum runoff coefficient, bamboo - Yang Tong - Hemerocallis mixed forest minimum. (2) the trend of runoff coefficient and nutrient flow loss was basically the same, and all showed significant fluctuation trend.
\end{abstract}

\section{Introduction}

Rainfall is one of the important factors which cause the loss of nutrients, and the characteristics of rainfall intensity and rainfall intensity have great influence on the surface runoff and nutrient loss. In addition, the intensity of rainfall and the degree of loss of nutrients and occurrence frequency and so on are closely related to [3-5]. The research on the relationship between rainfall and soil nutrient loss is one of the important contents of soil and water conservation scientific research work, which can provide scientific basis for the development of soil and water conservation project. Therefore, the selection of pure bamboo forest, bamboo forest and bamboo Tong Yang Yang Tong Hemerocallis mixed forest as the research object, analysis of rainfall intensity, runoff and nutrient loss as well as the relationship between rainfall and the latter, to explore the 3 types of forest soil erosion characteristics for forest type configuration and soil erosion provide on the basis of science.

\section{Research Method}

In the study area is set 3 vegetation configuration mode, respectively, of pure bamboo forest, bamboo forest, bamboo Tong Yang Yang Tong - Hemerocallis mixed forest, each vegetation configuration mode was repeated 2 times, that is a total of 9 residential runoff layout. The rainfall collection device was measured using a simple artificial rainfall level measuring device is installed in the open space, built-in water storage equipment, indoor with rain gauge. When rainfall occurs, the rainfall record time (date), rain water storage device and water storage, when rainfall at the end (about $1 \mathrm{H}$ rain), record the stop of rainfall time, and remove the water equipment, water consumption amount of cylinder volume record. Determination of runoff and sediment yield by measuring the depth of water in the pool when rainfall exceeds $20 \mathrm{~mm}$. If the water is clear, but not otherwise sampling; sampling time for cleaning tank. Determination of total nitrogen by alkaline potassium sulfate ultraviolet spectrophotometry (11894-89 GB), total phosphorus determination using vanadium molybdenum phosphoric acid colorimetric method.

\subsection{Rainfall Characteristics}

As shown in Figure 1, statistical analysis of the test area of 6-10 25 rainfall events, the following main characteristics: the rainfall and rainfall intensity and rainfall 6-10 month showed a fluctuating trend, the minimum rainfall is $6.0 \mathrm{~mm}$, the maximum rainfall is $106.0 \mathrm{~mm}$, rainfall mainly concentrated in the $30 \mathrm{~mm}$. The intensity of rainfall is the same as that of rainfall, which is obviously fluctuating, but the fluctuation pattern is slightly different from that of rainfall, which is 
related to the duration of rainfall. According to figure 1, the rainfall intensity between $0.18-5.67 \mathrm{~mm} / \mathrm{h}$. According to the rainfall intensity grade will be divided into: light rain rainfall intensity $(<0.42 \mathrm{~mm} / \mathrm{h})$, moderate $(0.42 \mathrm{~mm} / \mathrm{h}=<1.25 \mathrm{~mm} / \mathrm{h}$, heavy rain (rain) heavy rain and storm $1.25 \mathrm{~mm} / \mathrm{h}=\langle 2.5 \mathrm{~mm} / \mathrm{h})([13]=2.5 \mathrm{~mm} / \mathrm{h})$. Therefore, to divide the 25 rainfall intensity, rain that accounted for $4 \%$, moderate rain accounted for $36 \%$, accounted for $40 \%$, accounting for $20 \%$ of the rainfall, rainfall is moderate rain and heavy rain.

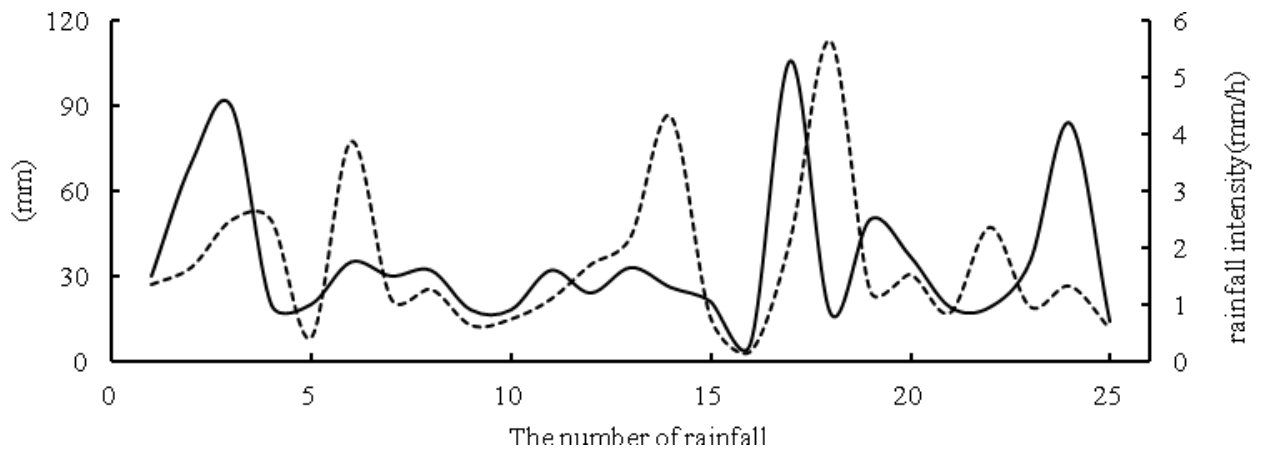

Fig. 1 the distribution of rainfall intensity and rainfall intensity

\subsection{Surface Runoff Dynamic}

The surface runoff dynamics of 3 kinds of forest stands were analyzed, and the results are shown in Figure 2. From Figure 2, we can know that the 3 types of runoff coefficient change trend is basically the same, there was a significant fluctuation trend, the maximum value appeared in June 19th, reaching $10 \%$, corresponding to heavy rain, the minimum value appeared in July 13th, only $0.7 \%$. June and August runoff coefficient is relatively large, in the collection of 11 rain, 5 heavy rain in June and August, and 5 of the 3 heavy rain in 4 fields are concentrated in more than two months. So the runoff coefficient in June and August is relatively large compared to the other two months. In addition, pure bamboo forest runoff coefficient is always greater than the other two stands.

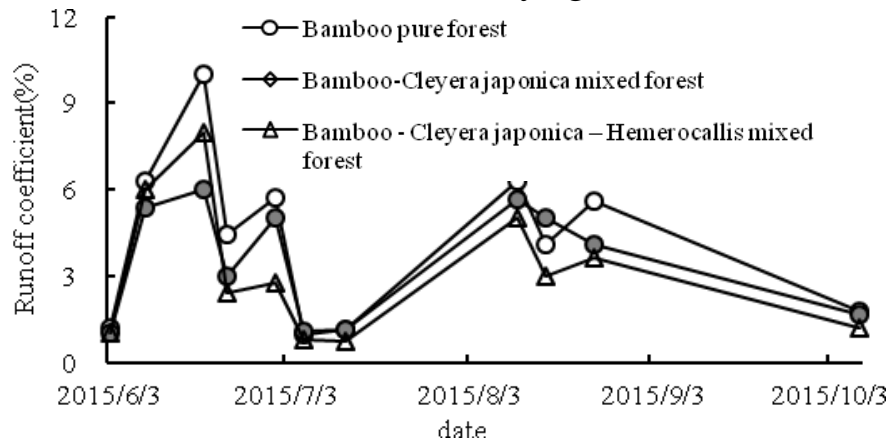

Fig. 2 dynamic variation of runoff coefficient

\subsection{Dynamics of Nutrient Loss}

The research on soil nutrient loss was mainly focused on the loss of total nitrogen and total phosphorus (Fig. 3 and 4). 6-10 analysis of 3 month loss of total nitrogen and total phosphorus content of the stand, the change trend of the two and the amount of soil loss is basically the same, were the highest in June, reached $10.62 \mathrm{~kg} / \mathrm{ha}$ and $0.15 \mathrm{~kg} / \mathrm{ha}$, the lowest in July, only $0.09 \mathrm{~kg} / \mathrm{ha}$ and $0.003 \mathrm{~kg} / \mathrm{ha}$. This is due to soil nutrients (i.e., total nitrogen and total phosphorus) attached to soil particles, when soil particles with runoff migration, surface runoff together with nutrient migration, causing nutrient loss. Similarly, compared with other two kinds of pure bamboo forest stand up nutrient loss. 


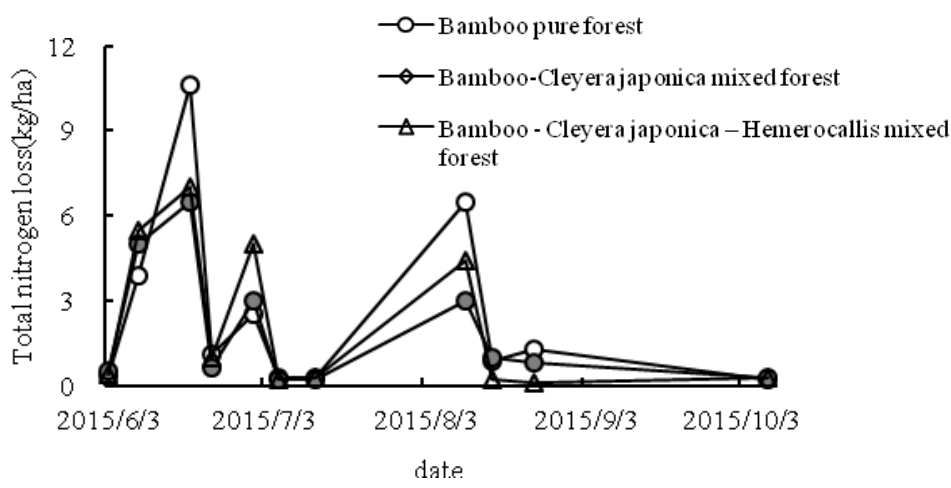

Fig. 3 dynamic changes of total nitrogen loss

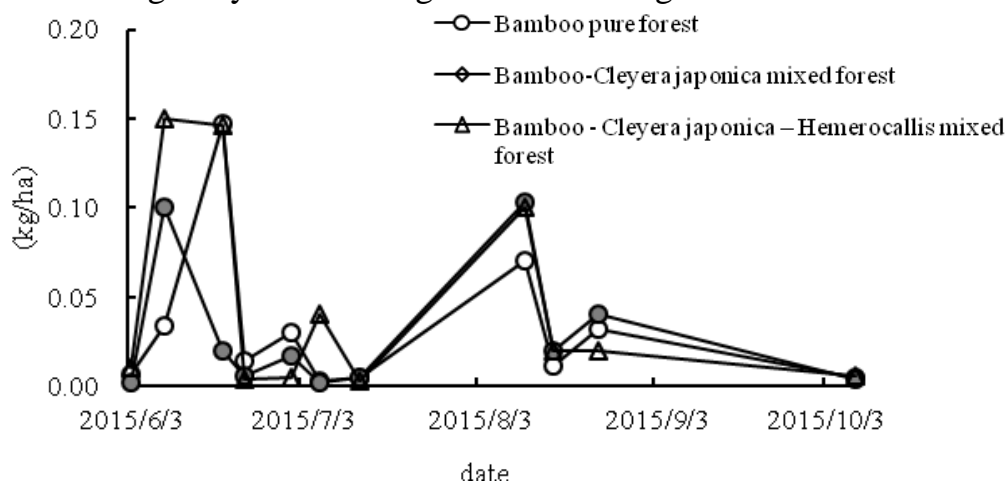

Fig. 4 dynamic changes of total phosphorus loss

\subsection{Relationship between Rainfall and Soil Erosion}

Application of Pearson on rainfall, runoff coefficient, soil loss, total nitrogen loss and total phosphorus loss for SPSS correlation analysis, found that there was a correlation between the various factors, R2 in 0.650-0.995. The rainfall and runoff coefficients were analyzed and the regression equation was constructed. The results were shown in Table 1.

Table 1 Regression Model of rainfall and surface runoff

\begin{tabular}{ccc}
\hline Sample type & regression equation & $R^{2}$ \\
\hline Pure bamboo & $\mathrm{y}=24.537 \mathrm{x}+4.599$ & 0.726 \\
Bamboo - Yang Tong & $\mathrm{y}=20.127 \mathrm{x}+6.794$ & 0.674 \\
Bamboo - Yang Tong - Lily & $\mathrm{y}=13.869 \mathrm{x}+1.978$ & 0.820 \\
\hline
\end{tabular}

\section{Conclusion}

(1) in the experimental area, the rainfall amount of 6-10 was obviously fluctuating, and the rainfall amount was $6.0-106.0 \mathrm{~mm}$. According to the rainfall intensity grade 25 rainfall is divided into light rain, moderate rain and heavy rain. The light rain, moderate rain accounted for $4 \%$, accounted for $36 \%$, accounted for $40 \%$ of the heavy rain, heavy rainfall accounted for $20 \%$, mainly for moderate rain and heavy rain.

(2) the rainstorm runoff coefficient is relatively high, followed by heavy rain, the rain. 3 stands in pure bamboo forest runoff coefficient is the largest, bamboo - Yang Tong - Hemerocallis mixed forest minimum. The trend of runoff coefficient and nutrient loss was basically the same, and all of which showed a trend of fluctuation.

\section{Acknowledgements}

This work was financially supported by Natural Science Foundation of Zhejiang Province of 
china(Grant No. LY14E090005), Department of Science and Technology of Zhejiang Province(Grant No. 2014F50015).

\section{Reference}

[1] Bi H X, Liu B, Wu J, et al.Effects of precipitation and Landuse on runoff during the past in a typical watershed 50 years in the loss plateau, China [J]. International Journal of Sediment Research, 2009, 24 (3): 352-364.

[2] Li Guang, Huang Gaobao. Effects of rainfall intensity and land use on Soil and water loss in Loess Hilly Region [J]. Journal of agricultural engineering, 2009, 25 (11): 85-90.

[3] Fang N F, Shi Z H, Li L, et al. The effects of rainfall regimes and land use changes on runoff and soil loss in a small mountainous watershed [J]. Catena, 2012(99): 1-8.

[4] Wei W, Chen L D, Fu B J, et al. The effect of land uses and rainfall regimes on runoff and soil erosion in the semi-arid loess hilly area, China [J]. Journal of Hydrology, 2007, 335 (3-4): 247-258.

[5] Yan Qinghong, Yuan Cuiping, Lei Tingwu, et al. Types of rainfall and soil and water conservation effect of soil erosion of small watershed in loess area [J]. Journal of agricultural machinery, 2014, 45 (2): 169-175. 